\title{
Violência Conjugal, Políticas Públicas e Rede de Atendimento: Percepção de Psicólogos(as)
}

\author{
Kamêni Iung Rolim \\ Universidade do Vale do Rio dos Sinos, RS, Brasil.
}

\author{
Denise Falcke \\ Universidade do Vale do Rio dos Sinos, RS, Brasil.
}

\begin{abstract}
Resumo: A violência nas relações conjugais tem sido alvo de diferentes políticas públicas, em dispositivos organizados na perspectiva do trabalho em rede. O presente estudo, exploratório e qualitativo, buscou conhecer a percepção de psicólogos(as) que trabalham nestes dispositivos, acerca do fenômeno da violência conjugal, das políticas públicas na área e inserção de psicólogos(as) na rede de atendimento. Participaram oito profissionais que responderam a uma entrevista semiestruturada. Identificou-se o predomínio da compreensão feminista sobre o fenômeno. Ademais, a violência conjugal foi considerada complexa e influenciada por questões socioeconômicas. Os participantes aferiram aspectos sobre manifestações da violência e seu ciclo, referindo que se trata de uma demanda pouco atendida em seus locais de trabalho. No que tange às políticas públicas, foram consideradas insuficientes para o atendimento da demanda $\mathrm{e}$ permeada por dificuldades de delimitação dos papéis e funções nos serviços. Consideram que ocorrem sobreposições de intervenções na rede de atendimento, que se mostra fragmentada e pouco articulada. Propõem-se reflexões acerca das potencialidades da Psicologia para fortalecimento da rede de atendimento e garantia de direitos para pessoas que vivenciam violência conjugal.
\end{abstract}

Palavras-chave: Violência Conjugal, Psicologia, Prática Profissional, Rede de Atendimento.

\section{Conjugal Violence, Public Policies and Service Network: Psychologists' Perceptions}

\begin{abstract}
Violence in conjugal relationships has been addressed by different public policies through social assistance devices organized from a network perspective. This exploratory qualitative study aimed to know how psychologists who work in these devices perceive conjugal violence, related public policies and the psychologist's insertion in the service network. Eight professionals responded to a semi-structured interview. We identified predominant feminist comprehension towards the phenomenon. Conjugal violence was considered complex and influenced by socioeconomic issues. Participants evaluated aspects on manifestations of violence and its cycle, reporting that this demand is not frequently met in their workplace. Concerning public policies, they were considered insufficient to meet the demands and permeated by difficulties in delimitating roles and functions in the services. Participants indicated overlapping interventions in the service network, which appears to be fragmented and scarcely articulated. We propose reflections on the potentiality of psychology to strengthen the network and guarantee the rights of people experiencing conjugal violence.
\end{abstract}

Keywords: Conjugal Violence, Psychology, Professional Practice, Service Network. 


\title{
La Violencia Conyugal, las Políticas Públicas y la Red de Servicio: Percepción de Psicólogos
}

\begin{abstract}
Resumen: La violencia en las relaciones de pareja ha sido objeto de políticas públicas, organizadas en la perspectiva de dispositivos en redes. Este estudio, de carácter exploratorio y cualitativo, tuvo como objetivo conocer la percepción de los psicólogos que trabajan en estos dispositivos, sobre el fenómeno de la violencia doméstica, las políticas públicas en el área y la inserción de los psicólogos en la red de servicios. Los participantes fueron ocho profesionales que respondieron a una entrevista semiestructurada. Se identificó el dominio de la comprensión feminista del fenómeno. Por otra parte, la violencia doméstica fue considerada compleja e influenciada por cuestiones socioeconómicas. Los participantes han evaluado aspectos de las manifestaciones de la violencia y su ciclo, señalando que es poca la demanda en sus lugares de trabajo. Las políticas públicas fueron consideradas insuficientes para satisfacer a la demanda y permeadas por las dificultades en la definición de los roles y funciones de los servicios. Los entrevistados consideran que las intervenciones se sobreponen en la red de servicios, que aparece fragmentada y mal articulada. Se proponen reflexiones sobre las posibilidades de la psicología para el fortalecimiento de la red de servicios y garantía de derechos a las personas que sufren violencia doméstica.
\end{abstract}

Palabras clave: Violencia Doméstica, Psicología, Práctica Profesional, Red de Servicios.

\section{Introdução}

A violência nas relações conjugais pode ser considerada um fenômeno sócio-histórico (Azambuja, \& Nogueira, 2007; Bhona, Lourenço, \& Brum, 2011), que, desde a década de 1990, tem sido apontado como um dos mais graves problemas sociais que impactam na saúde, em nível nacional (Brasil, 2005) e também em nível mundial (Azambuja, \& Nogueira, 2007; Minayo, 2007). Estudos apontam que situações de violência estão relacionadas ao aumento de manifestações de sintomas de ansiedade e depressão, abuso de substâncias (Afifi, Cox, \& Enns, 2006; Cascardi, O’Leary, \& Schlee, 1999; Ehrensaft, Moffit, \& Caspi, 2006), absenteísmo, índices mais altos de desemprego, maiores custos médicos (Bonomi, Anderson, Rivara, \& Thompson, 2009) e maior risco de ocorrência de agravos à saúde física dos envolvidos (Black, \& Breiding 2008).

Diante disso, a violência conjugal tem sido compreendida como um fenômeno complexo e multifatorial, que acarreta graves consequências biopsicossociais, em especial, problemas psicológicos, comportamentais, acadêmicos, sexuais, interpessoais e profissionais, além de quadros orgânicos (Day et al., 2003) e morte (Organização Mundial da Saúde [OMS], 2002). A violência perpetrada no ambiente familiar, por parceiros conjugais, configura-se como um dos principais tipos de violência notificados (Waiselfisz, 2012), com consequências para a saúde dos envolvidos não apenas durante, mas também após sua ocorrência. Neste sentido, em um estudo de coorte retrospectivo e comparativo, verificou-se que mulheres expostas a interações violentas com seus companheiros apresentaram custos significativamente maiores com sua saúde, na ocasião da violência, bem como nos três anos seguintes à cessação da situação (Fishman, Bonomi, Anderson, Reid, \& Rivara, 2010). A violência perpetrada nas relações amorosas também tem sido apontada como geradora de uma série de violações de direitos humanos (Monteiro, \& Zaluar, 2012) e causa de homicídio de mulheres no Brasil (Waiselfisz, 2012).

Verifica-se que existem diferentes abordagens teóricas que buscam compreender o fenômeno da violência nas relações conjugais. Alicerçadas nestas diferentes perspectivas e escolas de pensamento, que perpassam teorias e práticas (Oliveira, \& Souza, 2006), a violência nas relações amorosas tem sido denominada através de múltiplas nomenclaturas, por áreas de estudo como a Antropologia, a Criminologia, a Saúde Pública, a Sociologia e a Psicologia (Azambuja, \& Nogueira, 2007; Bhona, Lourenço, \& Brum, 2011).

Enfatizando relações de poder, a perspectiva de gênero (Bandeira, \& Oliveira, 1990; Casimiro, 2008; 
Dantas-Berger, \& Giffin, 2005; Gregori, 1993; Guedes, \& Fonseca, 2011) refere que a violência emerge da naturalização da desigualdade entre os gêneros e que existem padrões de violência que são historicamente construídos, a partir da ordem patriarcal. Em sintonia com essa perspectiva, Bhona et al. (2011), em estudo bibliométrico realizado no Brasil, apontam que as terminologias violência de gênero, violência contra a mulher e violência doméstica têm sido mais comumente utilizadas em estudos influenciados por diferentes vertentes do movimento feminista, que abordam a violência nas relações amorosas como sendo fenômeno que emerge a partir da naturalização da desigualdade entre os gêneros. Sobre esse aspecto, Saffioti (2001) salienta que, nas perspectivas feministas, gênero é compreendido como categoria histórica e analítica, ou seja, é fruto de uma modelagem social e não está relacionada ao sexo, embora este não seja um consenso entre diferentes modelos que abordam uma perspectiva de gênero e/ou feminista.

Neste sentido, autores apontam como manifestações do fenômeno a sujeição das mulheres e sua desqualificação como se fossem inferiores e desprovidas dos mesmos direitos dos homens (Gregori, 1993; Guedes, \& Fonseca, 2011). Para Dantas-Berger e Giffin (2005), uma ordem social de tradição patriarcal por muito tempo naturalizou padrões de violência contra a mulher e o movimento feminista foi o precursor nos estudos e nas intervenções nestas situações, trazendo notoriedade ao tema e impulsionando a criação dos primeiros serviços para atendimento à questão, sendo estes de apoio às mulheres vítimas.

Uma pesquisa, realizada por Lourenço et al. (2013), analisou 426 artigos publicados nas bases de periódicos Web of Science, PsycINFO, Dialnet, Lilacs e Redalyc, entre os anos de 2006 a 2011, e verificou que a maioria dos estudos abordavam a mulher como vítima. Dentre estes, $28,3 \%$ dos estudos contextualizavam o fenômeno como violência contra a mulher e 4,4\% como questão de gênero, além de problema de saúde pública $(25,2 \%)$ e problema social $(7,5 \%)$. Apenas 2,8\% dos estudos falavam sobre bidirecionalidade, assumindo que homens e mulheres podem ser agressores e vítimas e 1,5\% dos estudos abrangia a questão em relações homoafetivas. Outra constatação da revisão realizada pelos autores, corroborando Bhona et al. (2011), é que os periódicos têm utilizado termos mais específicos, em especial violência entre parceiros íntimos, em detrimento do termo violência doméstica, para se referir ao fenômeno.

Nas publicações abrangidas no estudo de Lourenço et al. (2013), a tipologia elaborada pelo sociólogo Michael Johnson (Emery, 2011; Johnson, 2006), que propõe uma classificação dos agressores a partir da dinâmica dos atos violentos perpetrados, foi uma das mais utilizadas para compreensão da violência. Identifica-se que essa abordagem tem sido utilizada sobremaneira para fomentar estratégias de intervenção que focam a assimetria homem-agressor e mulher-vítima, o que, para Holtzworth-Munroe (2000), pode ser explicado pelo fato de a violência perpetrada pelos homens ter consequências mais graves e aparentes.

A tipologia "Johnson" (Johnson, 2006) postula quatro tipos de interações violentas: Terrorismo íntimo, Resistência violenta, Violência situacional e Controle violento mútuo. O Terrorismo íntimo refere-se a quando um dos parceiros é violento e controlador, mas o outro não é; já a Resistência violenta ocorre quando a vítima, comumente a mulher (Peinado, Moura, Almeida, Souza, \& Gaspar, 2011), reage à violência sofrida, de forma contra-agressiva. Estes dois tipos de interações parecem ser os mais classicamente abordados por autores de propensão feminista (Peinado et al., 2011). Estas modalidades resultariam de um contexto de exercício de controle de um parceiro sobre o outro, de forma sistemática e através de manifestações de violência física, emocional, sexual e financeira.

AViolência situacional seria oriunda de uma situação pontual de discordância no relacionamento, ou seja, compreenderia manifestação de violência ocasional e não reiterada, oriunda de uma tensão familiar ou conjugal. O Controle violento mútuo compreenderia relações em que ambos os parceiros interagem de forma controladora, através do uso de violência. Johnson (2006) refere que a classificação das interações violentas em cada uma das modalidades descritas demandaria estratégias de atendimento diferenciadas, considerando o perfil da vítima e do agressor e o estágio da violência vivenciada. A Violência situacional e o Controle violento mútuo são subtipos focados por pesquisadores de abordagem sistêmica.

Pesquisadores de abordagem sistêmica optam por utilizar, em seus estudos, os termos violência no casal e violência conjugal por preconizarem o caráter relacional da violência. Neste sentido, a violência é compreendida como sendo um fenômeno interacional e as relações sociais de gênero são considera- 
das uma dentre outras variáveis que estão envolvidas na ocorrência de violência entre parceiros íntimos (Bhona, Lourenço, \& Brum, 2011; Oliveira, \& Souza, 2006), seja em relações hetero ou homoafetivas (Casimiro, 2008; Nunam, 2004).

Considerando a existência de uma multiplicidade de fatores envolvidos enquanto desencadeadores e mantenedores de situações de violência, incluindo emocionais, biológicos, cognitivos, sociais, comportamentais familiares e transgeracionais (Silva, Valadares, \& Souza, 2013), este enfoque contempla o fenômeno a partir da compreensão da dinâmica do ciclo de interações que se estabelecem entre um casal (Falcke, Oliveira, Rosa, \& Bentancur, 2009), ou seja, o foco está na relação violenta estabelecida na díade de forma interacional, através de um processo cíclico e progressivo.

Cabe salientar que Emery (2011), em artigo que abordou as diferentes tipologias de violência identificadas na literatura internacional, mostra que divergências entre as abordagens de gênero e a sistêmica emergiram nos primeiros estudos quantitativos acerca da violência doméstica. Estudos populacionais (Straus, \& Gelles, 1990), com base na Escala de Táticas de Conflito - CTS (Straus, 1979), apontaram que homens e mulheres em relacionamentos amorosos iniciavam e praticavam atos de violência em proporções semelhantes, o que provocou críticas por contestar o papel da mulher como exclusivamente vítima da violência no casal. Estes resultados também foram de encontro à premissa de que os homens são violentos e os únicos perpetradores da violência. Estudos com a CTS nos Estados Unidos identificaram taxas similares de atos violentos entre homens e mulheres, ao passo que estudos com a mesma escala na Coreia do Sul (Kim, \& Emery, 2003) indicaram que os homens praticavam mais atos violentos. No Brasil, estudo com 186 casais revelou que os homens perpetraram significativamente mais violência sexual, ao passo que mulheres perpetraram significativamente mais agressão psicológica, enquanto que os níveis de violência física perpetrada por homens e mulheres foram semelhantes (Colossi, Razera, Haack \& Falcke, 2015). Ainda que homens e mulheres possam se apresentar como vítimas e perpetradores em diferentes momentos, é necessária atenção para as diversas formas de manifestação da violência na conjugalidade e a severidade de sua ocorrência, bem como possíveis repercussões para o sistema familiar como um todo (Boeckel,
2013; McWhirter, 2010; Mosmann, \& Wagner, 2008; Overlien, 2010; Reichenheim, Dias, \& Moraes, 2006), em especial os danos causados aos filhos. Oliveira e Souza (2006) destacam as consequências negativas da violência não apenas para quem as sofre, mas também para quem as testemunha. Um estudo transversal, realizado por Reichenheim, Dias e Moraes (2006), que abordou a violência familiar no Rio de Janeiro, detectou tendência a agravos violentos ocorrerem englobando o grupo familiar como um todo, ou seja, interações violentas no casal tendem a ser acompanhadas também de violência contra os filhos. Neste sentido, Boeckel (2013) aferiu o impacto da violência conjugal em mulheres e seus filhos, verificando que a violência conjugal "transborda em toxicidades para além da mulher envolvida, incluindo especialmente os filhos deste casal com dificuldades relacionais" (p. 137). Já Mosmann e Wagner (2008) propuseram um modelo relacional da parentalidade e conjugalidade, evidenciando a mútua influência entre estes subsistemas familiares, ratificando a importância de abordar este processo nas intervenções clínicas.

Integrando aspectos que norteiam as perspectivas acima referidas, a Abordagem Bioecológica (Bronfenbrenner, 1979/2002, 2004), que é uma teoria multidimensional acerca do desenvolvimento humano, tem sido utilizada também para a compreensão do fenômeno das interações violentas no casal (Carvalho-Barreto, Bucher-Maluschke, Almeida, \& DeSouza, 2009). Contempla as inter-relações entre diferentes níveis, denominados Pessoal, Processual, Contextual e Temporal, configurando o modelo PPCT, que compreende a violência como produto das interfaces entre estas dimensões (Carvalho-Barreto et al., 2009).

O nível Pessoal abrange características biológicas, cognitivas, emocionais e comportamentais, que são dinâmicas e sofrem a influência de cada etapa do ciclo vital. O nível Processual se refere ao grau e características das relações do casal entre si e com outros sistemas. Já o nível Contextual está dividido em quatro subníveis (microssistema, mesossistema, exossistema e macrossistema), que se referem às relações estabelecidas entre sistemas próximos ao qual o casal faz parte, além de aspectos mais amplos da cultura social vigente. Podemos exemplificar estes contextos da seguinte forma: o microssistema pode contemplar a família, na qual o casal estabelece relações próximas e pelas quais é afetado. Já o mesossistema diz respeito às relações estabelecidas com as pessoas e locais da 
comunidade, tais como os vizinhos, a escola, o local de trabalho e a igreja. O exossistema contempla as interfaces com pessoas e locais que a pessoa não se relaciona diretamente, mas que o afetam de alguma forma. Por sua vez, o macrossistema refere-se a aspectos da cultura social vigente que podem se manifestar através da legislação e das representações sociais da violência, por exemplo. Já o nível temporal é explicado através do Cronossistema, que também é dividido em outros subníveis (microtempo, mesotempo e macrotempo); abrangendo a história da pessoa e das relações em diferentes períodos.

Identifica-se que diferentes abordagens, mas em especial as focadas na concepção de gênero, permeiam o atendimento de situações de violência nas relações conjugais (Conselho Federal de Psicologia [CFP], 2013; Oliveira, \& Souza, 2006). No Brasil, em especial na década de noventa, ações foram realizadas para promover o atendimento, em especial a mulheres em situação de violência, através de dispositivos como abrigos, organizações não governamentais e serviços da rede de atendimento socioassistencial e de saúde (CFP, 2013). O advento da Lei $\mathrm{n}^{\circ} 11.340$ (Brasil, 2006), também denominada Lei Maria da Penha, além de caracterizar os comportamentos que são considerados violência em relações amorosas, também fomentou a organização de diferentes políticas públicas através da perspectiva de rede de atendimento. Esta rede se caracteriza pela articulação entre instituições e serviços governamentais, não governamentais e sociedade civil.

Considerando que se trata de um tema recente e que as percepções dos profissionais se refletem em suas práticas (Nascimento, Ribeiro, \& Souza, 2014;
Oliveira, \& Souza, 2006), o presente estudo buscou conhecer as percepções de psicólogos(as) que atuam nos serviços que compõem a rede de atendimento a situações de violência conjugal do Vale do Paranhana, Rio Grande do Sul, acerca dos seguintes temas: concepções de violência conjugal, políticas públicas na violência conjugal e inserção de psicólogos(as) na rede de atendimento. Optou-se pela terminologia violência conjugal, buscando investigar todas as manifestações possíveis de violência no âmbito da conjugalidade.

\section{Método}

Foi realizado estudo qualitativo, de caráter exploratório (Gil, 2008), que privilegia o estudo de relações complexas, em profundidade (Turato, 2004). Para tal, foram convidados a participar todos os(as) psicólogos(as) que desenvolvem atividades nos serviços da rede de atendimento a situações de violência conjugal do Vale do Paranhana, Rio Grandes do Sul. Dos 10 psicólogos(as) que trabalham nestes serviços, oito aceitaram participar. Diante disso, participaram sete mulheres e um homem, com idades variando entre 27 e 40 anos. O tempo em que estão formados e trabalham como psicólogos(as) variou de 2 a 13 anos. Cinco participantes referiram possuir especialização. Em relação aos vínculos empregatícios, seis eram concursados, um cooperativado e um tinha cargo de confiança. A Tabela 1 apresenta dados sobre características dos participantes.

Para coleta dos dados, foi realizada uma entrevista semiestruturada, composta por questões que contemplam os objetivos do estudo, tais como: "Qual sua percepção sobre violência conjugal?", "Como avalia as políticas públicas voltadas às situações de

\section{Tabela 1}

Características dos participantes.

\begin{tabular}{lccc}
\hline Participante & Idade & Tempo de Formação & Especialização \\
\hline 1 & 34 & 6 anos & - \\
2 & 32 & 6 anos & Terapia de Revivência Transpessoal \\
3 & 36 & 10 anos & - \\
4 & 34 & 7 anos & Saúde Mental e Dependência Química \\
5 & 27 & 2 anos & - \\
6 & 30 & 4 anos & Dependência Química \\
7 & 26 & 2 anos & Psicanálise \\
8 & 38 & 13 anos & Políticas Públicas de Saúde Mental e Assistência Social \\
\hline
\end{tabular}


violência conjugal?" e "Como avalia a inserção do(a) psicólogo(a) na rede de atendimento a situações de violência conjugal?". Segundo Creswell (2010), a entrevista qualitativa se destina a suscitar as opiniões e concepções dos participantes.

Com o trabalho já aprovado pelo Comitê de Ética de Pesquisa da Unisinos sob Parecer $n^{\circ}$ 016/2015, foi realizado contato com psicólogos(as) de todos os serviços que compõem a rede de atendimento às situações de violência no Vale do Paranhana. Esta rede está composta por 13 serviços de atendimento geral e dois serviços de atendimento especializado à Mulher. Conforme a Política Nacional de Enfrentamento à Violência contra as mulheres (Brasil, 2011), os serviços de atendimento geral são aqueles que atendem a todos os públicos e são considerados portas de entrada para a rede de atendimento, devendo realizar o encaminhamento aos serviços especializados. No contexto desta pesquisa, tais serviços são os dispositivos do Sistema Único de Assistência Social (SUAS), que desenvolvem ações nos níveis de proteção social básica, orientadas para a prevenção, que ocorre nos Centros de Referência de Assistência Social (CRAS) e a proteção social especial, que diz respeito a intervenções quando as situações de violência já ocorreram, se dá nos Centros de Referência Especializado de Assistência Social (Creas). Além disso, as Defensorias Públicas Gerais também se enquadram na rede de serviços gerais e estão atuantes em todas as cidades que compõem o Vale do Paranhana, porém não haviam psicólogos compondo a equipe destes locais. Já os serviços especializados no atendimento à mulher, que atendem exclusivamente mulheres (Brasil, 2011), no contexto pesquisado, foram identificados dois, ambos localizados em uma das cidades pesquisadas: um Posto Policial de Atendimento à Mulher e um Centro de Referência de Atendimento à Mulher (CRAM), que não possuíam psicólogos em suas equipes. Diante disso, este estudo contemplou profissionais atuantes em seis CRAS e três Creas. Após assinatura do Termo de consentimento livre e esclarecido, conforme a Resolução no 466/2012 do Conselho Nacional de Saúde, a entrevista foi realizada em local escolhido pelo participante e gravada em áudio, para posterior transcrição.

As entrevistas foram transcritas e analisadas conforme os procedimentos da Análise de Conteúdo (Olabuénaga, 1999). Foram elaboradas três categorias de análise, definidas a priori, consoan- tes com as temáticas propostas nos objetivos. Conforme os conteúdos expressos em cada categoria, foram elaboradas subcategorias, visando caracterizar as percepções aferidas, das quais serão apresentados excertos representativos.

\section{Resultados e discussão}

A Tabela 2 apresenta as categorias e subcategorias de análise.

A Categoria de Análise 1, Percepções sobre violência conjugal, versa sobre o que os participantes referem sobre concepção, sinais, sintomas e reverberações da violência conjugal. Conforme a percepção dos participantes, a violência emerge “[...] da necessidade da mulher ser submissa, do abandono do lar, dos filhos, que a mulher acaba sendo vítima de uma situação" (Participante 3). Corroborando Dantas-Berger e Giffin (2005), Gregori (1993) e Guedes e Fonseca (2011), os participantes referem que tal fenômeno surge da existência de padrões de violência do homem em relação à mulher, que têm sido naturalizados na sociedade. Neste sentido, ressaltam que: "parece comum na nossa sociedade a mulher ser vítima, né, apanhar ou ser agredida verbalmente ou financeiramente ou ser imposta a certas situações" (Participante 3). Conforme Alberdi (2005) e Cantera (2007), esta naturalização e as desigualdades entre os gêneros são perpetuadas pelo machismo, componente que contribui para a compreensão de que os homens possuiriam mais força e competência do que a mulher, e que é decorrente de uma ordem social de tradição patriarcal (Dantas-Berger, \& Giffin, 2005).

Neste sentido, conforme a Participante 5:

Percebo que tem muito a ver com a questão cultural, assim, da própria família, do núcleo. Principalmente com relação à mulher, ao papel da mulher naquela família; então a mulher sempre é encarregada das tarefas da casa, tem que dar conta de ser uma boa mãe, uma boa esposa, de ter que trabalhar fora e muitas vezes assumir todas as responsabilidades da casa. O que me parece é que a mulher tem conseguido fazer vários papéis ao mesmo tempo, mas os maridos estão bastante acomodados assim, e exigindo coisas.

Identifica-se que muitas têm sido as mudanças em relação aos papéis familiares, ocorridos sobrema- 
Tabela 2

Categorias e subcategorias.

\begin{tabular}{|c|c|}
\hline Categorias & Subcategorias \\
\hline $\begin{array}{l}\text { 1. Percepções sobre violência conjugal } \\
\text { O que os participantes referem entender } \\
\text { sobre concepção, sinais, sintomas e } \\
\text { reverberações da violência conjugal }\end{array}$ & $\begin{array}{l}\text { Enfoque feminista } \\
\text { Concepção de que a violência ocorre pela assimetria de gênero entre } \\
\text { homens e mulheres } \\
\text { Questões econômicas } \\
\text { Compreensão de que aspectos financeiros estão envolvidos nas } \\
\text { situações de violência conjugal } \\
\text { Repercussões nos filhos } \\
\text { Compreensão de que a violência nas relações repercute nos filhos } \\
\text { Transgeracionalidade } \\
\text { Percepção de que a violência conjugal esteve presente em outras } \\
\text { gerações da família } \\
\text { Diferentes manifestações } \\
\text { Compreensão de que a violência conjugal se manifesta de } \\
\text { diferentes formas } \\
\text { Ciclo da violência } \\
\text { Entendimento de que a violência ocorre em ciclo que dificulta } \\
\text { desvincular da relação }\end{array}$ \\
\hline $\begin{array}{l}\text { 2. Políticas públicas } \\
\text { Opinião dos profissionais sobre a } \\
\text { implantação das políticas públicas }\end{array}$ & $\begin{array}{l}\text { Relevante, mas insuficiente } \\
\text { Percepção da importância e das dificuldades na execução dos } \\
\text { postulados nas políticas públicas } \\
\text { *Inserção da Psicologia nas políticas públicas } \\
\text { Dificuldades vivenciadas na inserção nos dispositivos das políticas } \\
\text { públicas }\end{array}$ \\
\hline $\begin{array}{l}\text { 3. Rede de atendimento } \\
\text { Refere-se à percepção dos } \\
\text { psicólogos(as) sobre sua participação na } \\
\text { rede de atendimento }\end{array}$ & $\begin{array}{l}\text { Demanda de atendimento } \\
\text { Identificação de que casos de violência conjugal dificilmente chegam por } \\
\text { demanda espontânea e que não têm sido atendidos nos CRAS e Creas } \\
\text { Dificuldades na rede de atendimento } \\
\text { Especificidades do fluxo da rede de atendimento que geram entraves } \\
\text { ao trabalho }\end{array}$ \\
\hline
\end{tabular}

neira com o ingresso da mulher no mercado de trabalho (França, \& Schimanski, 2009; Olinto, \& Oliveira, 2004). Contudo, alguns estereótipos que se configuram em prescrições normativas acerca do que é esperado em relação ao papel a ser desempenhado por homens e mulheres fundamentam desigualdades (Narvaz, \& Koller, 2006), as quais permeiam a ocorrência do que se denomina violência de gênero (Narvaz, 2005). Regulados por mitos e discursos, a expectativa de que a mulher seja "boa” mãe, "boa” esposa, que trabalhe fora e ainda cuide da casa pode ser considerada fruto de uma prescrição normativa patriarcal que legitima relações assimétricas entre homens e mulheres (Narvaz, \& Koller, 2006).

Os participantes também referem compreensão de que aspectos socioeconômicos estão envolvidos nas situações de violência conjugal. A Participante 6 considera que a violência nas relações amorosas é perpassada por “[...] questões financeiras envolvidas que não deixam a pessoa sair da relação". O exercício de controle de um parceiro sobre outro, inclusive através de questões financeiras é contemplado na tipologia "Johnson” (Johnson, 2006), ratificando a concepção feminista presente nas percepções dos participantes deste estudo (Peinado et al., 2011). Ademais, questões financeiras são apontadas como fator preditivo de interações conjugais violentas. Colossi et al. (2015), em estudo quantitativo com 186 casais, identificaram maiores níveis de agressão psicológica grave em casais com menor renda financeira, corroborando o estudo de Kronbauer e Meneghel (2005) e denotando que esta questão permeia a ocorrência de conflitos na relação.

Por outro lado, alguns participantes do estudo ressaltaram as repercussões da violência conjugal para outros subsistemas familiares, especialmente filhos. De acordo com a Participante 1, “[...] aparece pra nós muito mascarada por outros sintomas dos 
filhos e depois a gente identifica que há uma situação de violência psicológica [no casal]" e a Participante 6 considera que "Normalmente vêm de denúncia contra os filhos e a violência contra a mulher aparece, em geral verbal e às vezes física". Sobre este aspecto, Mosmann e Wagner (2008) e Reichenheim et al. (2006) salientam as reverberações e mútuas influências entre os subsistemas conjugal e parental, considerando que os membros da família, que convivem direta ou indiretamente com a violência, vivenciam sofrimento, que pode se manifestar de diferentes formas (Bhona, Stephan, Brum \& Lourenço, 2012; Boeckel, 2013).

Estas vivências na infância podem inclusive levar a reprodução de interações permeadas por violência no futuro. Segundo a Participante 5, “[...] vejo que tem muitas mulheres hoje que sofrem violência, elas também vêm com um contexto já na família assim, em que os pais também tinham problemas conjugais" e que "Às vezes, são questões de família que vêm de muitos anos, né". Este fenômeno é contemplado no conceito de transgeracionalidade. Falcke e Wagner (2005) referem que a transgeracionalidade se trata de aspectos da história familiar que são transmitidos de geração para geração e que podem ser repetidos ou reeditados. D'Oliveira, Schraiber, Hanada e Durand (2009) apontam que vivenciar ou testemunhar agressões físicas aumenta o risco de ocorrência de violência doméstica na vida adulta. Neste mesmo sentido, Marasca, Colossi e Falcke (2013), em revisão de literatura que abordou as produções acerca da temática violência conjugal e família de origem entre os anos de 2006 e 2011, identificaram estudos que apontam que vivenciar ou ter presenciado violência na família de origem serviu como preditor para ocorrência de interações violentas nos relacionamentos amorosos.

Outro aspecto referido pelos participantes foi acerca das manifestações de violência. As verbalizações mostram-se em consonância com os postulados pela Lei Maria da Penha (Brasil, 2006), que considera formas de violência a física, a psicológica, a sexual, a patrimonial e a moral. Conforme a Participante 6: “[...] olhando a situação é mais complicado, porque é preciso olhar para além das aparências, normalmente têm lesões físicas, psicológicas, menosprezo, baixa autoestima, questões financeiras envolvidas que não deixam a pessoa sair da relação". Ou ainda: "[...] principalmente por questão verbal, de como eles se tratam" (Participante 5).
Também foram referidas percepções acerca do ciclo da violência e das dificuldades vivenciadas para se desvincular da relação conjugal com interações violentas. Conforme a Participante 7, a mulher "[...] retira a queixa contra o marido, não representa, por que aí fazem as pazes. Aí voltam e está tudo bem; tem outro conflito de novo assim, e acaba se repetindo assim" (Participante 7). Sobre este aspecto, a Participante 6 afirma "Percebo que existe um sentimento de esperança de que o outro vai mudar, vai melhorar, surgem promessas, e as pessoas acabam se apegando ao detalhe que mudou. Desvincular é muito difícil". Reforçando a dificuldade de rompimento do ciclo, a Participante 3 comenta: “[...] eu penso, hã, as mulheres muitas vezes não conseguem sair disso, não sei, né?”. Esta percepção remete ao ciclo da violência (Walker, 1979), que refere aspectos da dinâmica conjugal violenta, compreendendo que estas interações ocorrem em ciclo que alterna momentos de violência com momentos de harmonia conjugal, caracterizados por promessas de que não mais ocorrerá violência (Falcke, \& Féres-Carneiro, 2011). Hirigoyen (2006) afirma que, após instalado este ciclo, os conflitos, seguidos das promessas de que não mais ocorrerão, vão acontecendo em intervalos de tempo cada vez menores, fazendo com que a pessoa passe a tolerar e justificar a violência.

O conteúdo da Categoria 1 revela uma concepção de violência na perspectiva de gênero e que ressalta a dificuldade de rompimento da violência e sua perpetuação entre diferentes gerações de uma mesma família. Neste sentido, sobressai-se a visão da mulher vítima, definida pelo papel social a ela atribuído (Bandeira, \& Oliveira, 1990; Casimiro, 2008; Dantas-Berger, \& Giffin, 2005).

As percepções de psicólogos(as) acerca das políticas públicas para atendimento às situações de violência foram aferidas na Categoria 2, Políticas públicas. Conforme Souza (2006), as políticas públicas tratam-se de um campo holístico, multidisciplinar, que envolve a proposição, implementação, execução e avaliação de ações governamentais. São realizadas pelos governos através de ações e programas, incluindo entes públicos e privados. No que tange às políticas públicas voltadas ao atendimento de situações de violência, em especial à Lei Maria da Penha (Brasil, 2006) e à implementação dos dispositivos da rede de atendimento, tais como Delegacias da Mulher e o SUAS, a Participante 6 afirma que se trata de "[...] 
política extremamente positiva, em termos do que realmente se consegue oferecer, mas está longe do necessário" (Participante 6). Em relação a esta percepção de insuficiência e distanciamento entre teoria e prática, a Participante 5 refere "[...] que tem poucas políticas em relação, claro, avançou desde a Lei, da organização destes espaços, das Delegacias pra Mulher, mas aqui no município eu vejo que tem assim, não tem, na verdade, muita opção, não tem muita política voltada a este público" (Participante 5).

Consoante com Cavalcanti (2006) e Martes, Arretche, Melo e Ribeiro (1999), alguns aspectos contribuem para o distanciamento entre formulação e realização das políticas públicas. Os autores destacam que, muitas vezes, os trabalhadores que operacionalizam as políticas não recebem informações claras acerca dos objetivos dos programas, existindo discordâncias entre os objetivos das políticas e os objetivos dos operadores, os problemas de ordem administrativa e a necessidade de adaptação das políticas à realidade de cada local. Costa e Castanhar (2003) destacam que, historicamente, a formulação de políticas públicas tem recebido mais atenção do que a própria implantação dos programas, salientando ainda a importância de que sejam realizadas avaliações constantes para garantir que os programas sejam implantados e realizados com efetividade.

No que tange à inserção da Psicologia nas políticas públicas, os participantes referem que se trata de um campo novo de trabalho para a Psicologia e, por isso, ainda necessita de clareza para a atuação:

\section{[...] não era uma área em que a Psicologia se apro- priava, e até pouco tempo também não, agora que tem esses movimentos recentes de apropriação dessa política, e eu acho que o maior desafio é esse. Alguém olha pra ti e pergunta: o que faz uma psi- cóloga na assistência? E segurança, e tu ter segu- rança pra dizer, porque eu não tenho, eu já per- guntei pra vários (Participante 7).}

A implantação do SUAS é considerada recente (Afonso, Hennon, Carico, \& Peterson, 2013; Hanada, D’Oliveira, \& Schraiber, 2010; Silva, \& Corgozinho, 2011) e ainda pouco abordada na formação profissional (Cruz, 2009; Scarparo, \& Guareschi, 2007; Senra, 2009), propiciando que a inserção do(a) psicólogo(a) no SUAS seja permeada por sensações como surpresa e inseguranças (Vasconcelos, 2011).
Também é ressaltada a vivência de dificuldades. A Participante 7 afirma "Eu vejo que a política pública, seja da assistência ou da saúde, ela é um apêndice, ela é um apoio, é uma bengala pras pessoas, pra sustentar a clínica particular, e é por isso que muitas vezes o trabalho é uma porcaria, né?". Esse dado corrobora a observação de Vasconcelos (2011) de que muitos profissionais optam por trabalhar em programas sociais com vistas a obter estabilidade financeira para manter a clínica particular. Diante disso, identifica-se que os conteúdos aferidos na Categoria 2 denotam sobremaneira percepções de insuficiência das políticas públicas, por não atenderem de forma efetiva a demanda, bem como dificuldades quanto a definições do papel e funções a serem assumidos pelo(a) psicólogo(a), em especial nos dispositivos do SUAS (Vasconcelos, 2011).

$\mathrm{Na}$ Categoria 3, Rede de atendimento, foi possível aferir que os(as) psicólogos(as) participantes consideram que as demandas de violência conjugal dificilmente chegam à rede de atendimento por meio de demanda espontânea e que não têm sido atendidas nos serviços onde atuam. Sobre este aspecto, a Participante 6 afirma que seria necessária melhor articulação "[...] para que os casos sejam encaminhados e conhecidos pelo nosso serviço, porque não estão chegando até nós" (Participante 6) e que "[...] os casos vêm de algum outro encaminhamento, nunca vêm de procura espontânea" (Participante 6). Sobre este aspecto, Bedone e Faúndes (2007), Meneghel, Bairros, Mueller, Monteiro, Oliveira e Collaziol (2011) e Villela e Lago (2007) referem que pessoas que vivenciam a violência conjugal tendem a minimizar o problema e vivenciar vergonha, culpa e baixa autoestima, que podem ser dificultadores para que a pessoa venha a denunciar a situação ou buscar atendimento de forma espontânea. Ademais, Meneghel et al. (2011) apontam que o serviço em rede fragmentada amplia as vulnerabilidades vivenciadas e dificulta o rompimento do ciclo da violência. Nesse estudo, se identifica que os setores que prestam o atendimento jurídico não estão referenciando as famílias atendidas para realização de acompanhamento nos locais onde os(as) psicólogos(as) trabalham, denotando esta fragmentação (Meneghel et al., 2011).

Por outro lado, alguns participantes afirmam receber estes encaminhamentos, mas vivenciam dificuldades para que as pessoas iniciem o atendimento. A Participante 8 revela que 
[...] só de Maria da Penha eu não atendo, por que não chega hoje, como eu te disse, praticamente não chega, quando chega é uma ou outra vez, o oficio do Fórum e que daí se chama a vítima, o agressor e eles nunca vêm. Eu penso que quando tem isso, se vai direto pra Coordenadoria da Mulher (Participante 8).

Neste sentido, afirma a Participante 7, “[...] nem posso te dizer como é feita a intervenção porque não se teve, a família não quis, não desejou, nê'. Pode-se afirmar que o impacto e complexidade das situações de violência são desafios para a criação/manutenção de intervenções eficientes (Falcke, \& Féres-Carneiro, 2011).

Além da fragmentação da rede e do impacto das situações de violência, no contexto deste estudo, percebe-se que a percepção dos(as) psicólogos(as), manifestada pelo discurso de que as pessoas não são encaminhadas ou não chegam ao atendimento quando chamadas pode ser uma forma sutil de culpabilização através da retórica defensiva (Soares, 2002), que se refere à transferência de responsabilidade para outro serviço ou profissional. A ocorrência deste fenômeno também foi observada por Meneghel et al. (2011) em estudo realizado com operadores da rede de atendimento de Porto Alegre. Neste sentido, Saforcada (2010), em análise realizada a partir da abordagem ecológica-sistêmica da saúde, refere que nos dispositivos das políticas públicas incidem subjetividades e comportamentos institucionais que impactam em dinâmicas entre profissionais e os usuários dos serviços. Por retroalimentação, estes aspectos, dentre outros, contribuem para o que denomina uma obstaculização do desenvolvimento humano, através da adoção de práticas burocratizadas, anomia e comportamentos autocráticos. Também foram referidas percepções acerca do fluxo entre os serviços. É percebido que "[...] falta compreensão do que cada local faz, e isso independe de ser CRAS, de ser Creas, de ser um abrigo, enfim. Isso é de todos os serviços, é ter uma maior divulgação do que é cada um, poder sentar, ter um diálogo" (Participante 7). Neste sentido, a Participante 7 também refere: “[...] a gente tem feito desta maneira, muitas vezes acolhendo demandas que nem são do Creas, mas pelo cansaço de tentar se fazer entender, tem essa dificuldade". A dificuldade de compreensão do que é feito em cada serviço bem como a sobreposição de atividades entre eles também foram identificadas como dificuldades vivenciadas por profissionais em outros estudos no contexto brasileiro (Kiss, Schraiber, \& D'Oliveira, 2007; Meneghel et al., 2011).

Sendo assim, o conteúdo da Categoria 3 denota as dificuldades percebidas pelos profissionais no que tange à rede de atendimento. A não procura espontânea, o fluxo truncado entre os serviços e a falta de clareza ou sobreposição de funções entre os mesmos são percebidos como dificultadores do acesso das pessoas ao atendimento. Ademais a dificuldade de acesso e adesão das pessoas ao atendimento também tende a ser atribuída à falta de desejo das pessoas em comparecerem quando chamadas. Tais aspectos remetem ao fenômeno de transferência de responsabilidade a partir da retórica defensiva (Meneghel et al., 2011; Soares, 2002).

\section{Considerações finais}

Os resultados revelaram aspectos sobre manifestações da violência, partindo de uma concepção essencialmente feminista e seu ciclo. Conforme Guedes e Fonseca (2011) e Gregori (1993), a desigualdade entre os gêneros e a desqualificação do feminino como oriundos de uma herança da ordem social patriarcal (Guedes, \& Fonseca, 2011, Gregori, 1993) contribuem para a visão de que a mulher é essencialmente vítima (Gregori, 1993). Diante disso, pode-se afirmar que esta percepção pode levar à repetição de processos de exclusão. O questionamento que se pode fazer, neste caso, é o quanto uma visão preconcebida do fenômeno pode ser limitadora da compreensão do mesmo em suas múltiplas expressões. Oliveira e Souza (2006) questionam se, como psicólogos(as), não se corre o risco de cometer violência ao olhar para a mulher sempre como vítima e para o homem sempre como agressor

Além disso, verifica-se que, mesmo com campanhas para a denúncia e notificação dos casos de violência, parece ainda haver dificuldade de acesso dos envolvidos à rede de atendimento. Os participantes referem que se trata de uma demanda ainda pouco atendida em seus locais de trabalho e atribuem que esta situação se deve sobremaneira à fragmentação da rede de atendimento, que não realiza os encaminhamentos pertinentes; à dificuldade das pessoas se desvincularem de uma relação violenta, explicada a partir de aspectos do ciclo da violência (Hirigoyen, 2006; Walker, 1979), e à percepção de que as pessoas não têm o desejo de participar do atendimento ofertado. Neste sentido, pode-se afirmar que essas per- 
cepções têm permeado a adoção de intervenções que acabam por preconizar atendimentos de emergência, quando a violência já ocorreu (Meneghel et al., 2011), em detrimento de ações continuadas, sistemáticas ou até mesmo preventivas.

Diante disso, é possível afirmar que esta situação contribui para a não constituição de um vínculo entre profissional e pessoa que necessita do atendimento, obstaculizando práticas psicossociais, tais como o acompanhamento sistemático desta pessoa ou família. A ausência de ações preventivas, no nível de prevenção primária, buscando evitar a ocorrência da violência, também influencia na adoção de atendimentos de emergência (Meneghel et al., 2011).

No que tange às políticas públicas, foram consideradas relevantes, porém insuficientes para o atendimento da demanda e permeada por dificuldades de delimitação dos papéis e funções entre os profissionais que compõem os serviços. Ademais, consideram que ocorrem sobreposições de intervenções na rede de atendimento, que se mostra fragmentada, pouco articulada. Pode-se considerar que a carga de vivências negativas que se estabelece na dinâmica relacional que se estabelece entre os profissionais, os usuários e a rede relacionam-se a processos de degradação para todos os envolvidos. A insegurança em relação ao que pode ou não ser realizado pelos psicólogos(as) que integram os serviços pode também ser resultante justamente destes processos. Tais aspectos têm permeado a inserção do(a) psicólogo(a) nas políticas públicas (Biasus, \& Franceschi, 2015; Silva, \& Corgozinho, 2011; Vasconcelos, 2011). Neste sentido, Silva e Carvalhaes (2016) destacam que os impasses e possibilidades da atuação dos(as) psicólogos(as) nas políticas públicas são marcados por construções históricas, permeadas por diferentes paradigmas de pensamento.

Ademais, é possível considerar que estes profissionais têm sido impactados pelas demandas atinentes à inserção em dispositivos que foram implantados recentemente, e pouco contemplados em sua formação profissional (Cruz, 2009; Scarparo, \& Guareschi, 2007; Senra, 2009), acarretando com que sua a inserção neste contexto seja permeada por sensações como surpresa e inseguranças (Vasconcelos, 2011). Considera-se que, por muito tempo, a Psicologia no Brasil esteve calcada em um modelo paradigmático clínico individualizante, focado sobremaneira na subjetividade (Vasconcelos, 2011), modelo este que têm sido o mais abordado nas graduações em Psicologia
(Abdalla, 2007, Scarparo, \& Guareschi, 2008; Teixeira, 1997). Problematiza-se que a tentativa de replicar este modelo seja um fator dificultador da inserção dos(as) psicólogo(as) no contexto estudado.

Por outro lado, ressalta-se as potencialidades da Psicologia para fortalecimento da rede de atendimento e garantia de direitos para pessoas que vivenciam violência conjugal, a partir da ampliação da compreensão das múltiplas expressões do fenômeno e através de ações que busquem o fortalecimento de pessoas, famílias e comunidades. Considera-se que estas ações podem ser balizadas a partir das concepções da Clínica Ampliada (Carvalho, \& Sampaio, 1997; Enriquez, 1997; Scarparo, \& Guareschi, 2007), que está focada em práticas psicossociais que visam contemplar múltiplas dimensões dos fenômenos sociais e psíquicos, que são compreendidos em interação. Nesta perspectiva, a inclusão de membros da família nas intervenções é recomendada, considerando que as repercussões da violência atingem os demais subsistemas, além do conjugal (Bhona, Lourenço, \& Brum, 2011; Lourenço et al., 2011; McWhirter, 2010; Oliveira, \& Souza, 2006). Neste sentido, percebe-se que a inclusão dos homens nos atendimentos se constitui em um importante passo para que esta rede execute ações efetivas e que promovam novas formas de interação na família, sem a presença ou com a redução de manifestações de violência.

Destaca-se a importância de inclusão da díade conjugal, bem como da família e da rede de apoio social, nas intervenções realizadas, buscando o fomento de fatores de proteção e a redução de fatores de risco para a ocorrência de violência nas relações amorosas. Considerando o contexto do SUAS, tais intervenções podem ocorrer a partir da adoção de ações em promoção de saúde, visando a aproximação com o contexto, através de estratégias tais como os grupos na comunidade - grupos de pais, de casais e multifamiliares (Narvaz, 2010), busca ativa, visitas domiciliares e palestras, dentre outras práticas.

Considera-se que a implantação de políticas públicas de desenvolvimento social é fundamental na área da saúde mental, podendo contribuir para o enfrentamento deste grave problema de saúde pública que é a violência conjugal. Neste sentido, abordagens calcadas na perspectiva da Clínica Ampliada podem promover saúde e desenvolvimento em diferentes níveis relacionais, em especial nos âmbitos familiares e comunitários. 


\section{Referências}

Abdalla, I. G. (2007). O ensino de psicologia clínica na graduação: uma análise a partir de psicólogos clínicos docentes e não docentes. Revista Brasileira de Educação Médica, 31(2), 190. https://doi.org/10.1590/S010055022007000200012

Afifi, T. O., Cox, B. J., \& Enns, M. W. (2006). Mental health profiles among married, never-married, and separated/ divorced mothers in a nationally representative sample. Social Psychiatry and Psychiatric Epidemiology, 41(2), 122-129. https:// doi.org/10.1007/s00127-005-0005-3

Afonso, M. L. M., Hennon, C. B., Carico, T. L., \& Peterson, G. W. (2013). A methodological approach for working with families in SUAS: a critical reading through the lens of citizenship. Psicologia \& Sociedade, 25(no. spe), 80-90. https://doi.org/10.1590/S0102-71822013000500010

Alberdi, I. (2005). Cómo reconocer y cómo erradicar la violencia contra las mujeres. In Programa de Prevención de la Obra Social la Caixa, Violencia: tolerancia cero (pp. 9-87). Barcelona: Fundación la Caixa.

Azambuja, M. P. R., \& Nogueira, C. (2007). Violência de gênero: uma reflexão sobre a variabilidade nas terminologias. Saúde em Debate, 31(75-77), 97-106. Recuperado de https://repositorio-aberto.up.pt/bitstream/10216/64336/2/90838.pdf

Bandeira, L. M., \& Oliveira, E. M. (1990). Trajetória da produção acadêmica sobre as relações de gênero nas ciências sociais. Trabalho apresentado no XIX Encontro Anual da ANPOCS, Caxambu, MG.

Bedone, A. J., \& Faúndes, A. (2007). Atendimento integral às mulheres vítimas de violência sexual: Centro de Assistência Integral à Saúde da Mulher, Universidade Estadual de Campinas. Cadernos de Saúde Pública, 23(2), 465469. https://doi.org/10.1590/S0102-311X2007000200024

Bhona, F. M. C., Lourenço, L. M., \& Brum, C. R. S. (2011). Violência doméstica: um estudo bibliométrico. Arquivos Brasileiros de Psicologia, 63(1), 87-100. Recuperado de http://pepsic.bvsalud.org/pdf/arbp/v63n1/v63n1a10.pdf

Bhona, F. M. C., Stephan, F., Brum, C. R. S., \& Lourenço, L. M. (2012). Violência doméstica e adolescência: levantamento bibliométrico. Gerais: Revista Interinstitucional de Psicologia, 5(1), 165-183. Recuperado de http://pepsic. bvsalud.org/pdf/gerais/v5n1/v5n1a11.pdf

Biasus, F., \& Franceschi, M. (2015). O psicólogo no CRAS: características e desafios da atuação profissional. Revista de Psicologia da IMED, 7(1), 23-34. https://doi.org/10.18256/2175-5027/psico-imed.v7n1p23-34

Black, M. C., \& Breiding, M. J. (2008). Adverse health conditions and health risk behaviors associated with intimate partner violence: United States, 2005. The Journal of the American Medical Association, 300(6), 646-649. https://doi.org/10.1001/jama.300.6.646

Boeckel, M. G. (2013). Ambientes familiares tóxicos: Impactos da violência conjugal na vinculação entre mães e filhos, no reconhecimento de emoções e nos níveis de cortisol (Tese de Doutorado). Pontifícia Universidade Católica do Rio Grande do Sul, Porto Alegre, RS.

Bonomi, A. E., Anderson, M. L., Rivara, F. P., \& Thompson, R. S. (2009). Health care utilization and costs associated with physical and nonphysical-only intimate partner violence. Health Services Research, 44(3), $1052-1067$. https://doi.org/10.1111/j.1475-6773.2009.00955.x

Brasil. (2006, 8 de agosto). Lei 11.340, de 7 de agosto de 2006. Cria mecanismos para coibir a violência doméstica e familiar contra a mulher, nos termos do § 80 do art. 226 da Constituição Federal, da Convenção sobre a Eliminação de Todas as Formas de Discriminação contra as Mulheres e da Convenção Interamericana para Prevenir, Punir e Erradicar a Violência contra a Mulher; dispõe sobre a criação dos Juizados de Violência Doméstica e Familiar contra a Mulher; altera o Código de Processo Penal, o Código Penal e a Lei de Execução Penal; e dá outras providências. Diário Oficial da União.

Brasil. Ministério da Saúde. Secretaria de Vigilância em Saúde. (2005). Impacto da violência na saúde dos brasileiros. Brasília, DF: Autor. Recuperado de http://bvsms.saude.gov.br/bvs/publicacoes/impacto_violencia.pdf

Brasil. (2011). Secretaria de Políticas para as Mulheres, Secretaria Nacional de Enfrentamento à Violência contra as Mulheres. Rede de Enfrentamento à Violência contra as Mulheres. Brasília, DF: o autor.

Bronfenbrenner, U. (2002). A ecologia do desenvolvimento humano: experimentos naturais e planejados (M. A. V. Veronese, Trad.). Porto Alegre, RS: Artmed. (Original publicado em 1979). 
Bronfenbrenner, U. (Ed.). (2004). Making human beings human: bioecological perspectives on human development. Thousand Oaks, CA: Sage.

Cantera, L. M. (2007). Casais e violência: um enfoque além do gênero. Porto Alegre, RS: Dom Quixote.

Carvalho, M. T. M., \& Sampaio, J. R. (1997). A formação do psicólogo e as áreas emergentes. Psicologia: Ciência e Profissão, 17(1), 14-19. https://doi.org/10.1590/S1414-98931997000100003

Carvalho-Barreto, A., Bucher-Maluschke, J. S. N. F., Almeida, P. C., \& DeSouza, E. (2009). Desenvolvimento humano e violência de gênero: uma integração bioecológica. Psicologia: Reflexão e Crítica, 22(1), 86-92. https:// doi.org/10.1590/S0102-79722009000100012

Cascardi, M., O'Leary, K. D., \& Schlee, K. A. (1999). Co-occurrence and correlates of posttraumatic stress disorder and major depression in physically abused women. Journal of Family Violence, 14(3), 227-249. https://doi.org/10.1023/A:1022827915757

Casimiro, C. (2008). Violências na conjugalidade: a questão da simetria do gênero. Análise Social, 43(3), 579-601. Recuperado de http://analisesocial.ics.ul.pt/documentos/1222271301F5hRJ2yz1Oz55WJ0.pdf

Cavalcanti, M.M.A. (2006). Avaliação de políticas públicas e programas governamentais: uma abordagem conceitual. Recuperado de http://www.socialiris.org/antigo/imagem/boletim/arq48975df171def.pdf

Colossi, P. M., Razera, J., Haack, K. R., \& Falcke, D. (2015). Violência conjugal: prevalência e fatores associados. Contextos Clínicos, 8(1), 55-66. https://doi.org/10.15448/1980-8623.2017.2.25148

Conselho Federal de Psicologia - CFP. (2013). Referências técnicas para atuação de psicólogas(os) em Programas de Atenção à Mulher em situação de violência. Brasília, DF: Autor.

Costa, F. L., \& Castanhar, J. C. (2003). Avaliação de programas públicos: desafios conceituais e metodológicos. Revista de Administração Pública, 37(5), 962-969. Recuperado de http://bibliotecadigital.fgv.br/ojs/index.php/ $\mathrm{rap} /$ article/view/6509/5093

Creswell, J. W. (2010). Projeto de pesquisa: métodos qualitativo, quantitativo e misto (3a ed., M. Lopes, Trad.). Porto Alegre, RS: Artmed.

Cruz, J. M. (2009). Práticas psicológicas em Centro de Referência de Assistência Social (CRAS). Psicologia em Foco, 2(1), 11-27. Recuperado de http://linux.alfamaweb.com.br/sgw/downloads/161_073535_ARTIGO2-PraticaspsicologicasemCRAS.pdf

D’Oliveira, A. F. P. L., Schraiber, L. B., Hanada, H., \& Durand, J. (2009). Atenção integral à saúde de mulheres em situação de violência de gênero: uma alternativa para a atenção primária em saúde. Ciência \& Saúde Coletiva, 14(4), 1037-1050. https://doi.org/10.1590/S1413-81232009000400011

Dantas-Berger, S. M., \& Giffin, K. (2005). A violência nas relações de conjugalidade: Invisibilidade e banalização da violência sexual? Cadernos de Saúde Pública, 21(2), 417-425. https://doi.org/10.1590/S0102-311X2005000200008

Day, V. P., Telles, L. E. B., Zoratto, P. H., Azambuja, M. R. F., Machado, D. A., Silveira, M. B. et al. (2003). Violência doméstica e suas diferentes manifestações. Revista de Psiquiatria do Rio Grande do Sul, 25(suppl 1), 9-21. https:// doi.org/10.1590/S0101-81082003000400003

Ehrensaft, M. K., Moffit, T. E., \& Caspi, A. (2006). Is domestic violence followed by an increased risk of psychiatric disorders among women but not among men? A longitudinal cohort study. American Journal of Psychiatry, 163(5), 885-892. https://doi.org/10.1176/ajp.2006.163.5.885

Emery, C. R. (2011). Disorder or deviant order? Re-theorizing domestic violence in terms of order, power and legitimacy. Aggression and Violent Behavior, 16(6), 525-540. https://doi.org/10.1016/j.avb.2011.07.001

Enriquez, E. (1997). A organização em análise. Petrópolis, RJ: Vozes.

Falcke, D., \& Féres-Carneiro, T. (2011). Reflexões sobre a violência conjugal: Diferentes contextos, múltiplas expressões. In A. Wagner (Ed.), Desafios psicossociais da família contemporânea (pp. 72-85). Porto Alegre, RS: Artmed.

Falcke, D., Oliveira, D., Rosa, L., \& Bentancur, M. (2009). Violência conjugal: um fenômeno interacional. Contextos Clínicos, 2(2), 81-90. https://doi.org/10.4013/ctc.2009.22.02

Falcke, D., \&Wagner, A. (2005). A dinâmica familiar e o fenômeno da transgeracionalidade: definição de conceitos. In A. Wagner (Ed.), Como se perpetua a família? A transmissão dos modelos familiares (pp. 25-46). Porto Alegre, RS: EDIPUCRS. 
Fishman, P. A., Bonomi, A. E., Anderson, M. L., Reid, R. J., \& Rivara, F. P. (2010). Changes in health care costs over time following the cessation of intimate partner violence. Journal of General Internal Medicine, 25(9), 920-925. https://doi.org/10.1007/s11606-010-1359-0

França, A. L., \& Schimanski, E. (2009). Mulher, trabalho e família: uma análise sobre a dupla jornada feminina e seus reflexos no âmbito familiar. Emancipação, 9(1), 65-78. Recuperado de http://www.uepg.br/emancipacao

Gil, A. C. (2008). Métodos e técnicas de pesquisa social (6a ed.). São Paulo, SP: Atlas.

Gregori, M. F. (1993). Cenas e queixas: um estudo sobre mulheres, relações violentas e a prática feminista. São Paulo, SP: Paz e Terra.

Guedes, R. N., \& Fonseca, R. M. G. S. (2011). A autonomia como necessidade estruturante para o enfrentamento da violência de gênero. Revista da Escola de Enfermagem da USP, 45(2), 1731-1735. https://doi.org/10.1590/S008062342011000800016

Hanada, H., D’Oliveira, A. F. P. L., \& Schraiber, L. B. (2010). Os psicólogos na rede de assistência a mulheres em situação de violência. Revista Estudos Feministas, 18(1), 33-60. https://doi.org/10.1590/S0104-026X2010000100003

Hirigoyen, M.-F. (2006). A violência no casal: da coação psicológica à agressão física. Rio de Janeiro, RJ: Bertrand Brasil.

Holtzworth-Munroe, A. (2000). A typology of men who are violent toward their female partners: making sense of the heterogeneity in husband violence. Current Directions in Psychological Science, 9(4), $140-143$. https://doi.org/10.1111/1467-8721.00079

Johnson, M. P. (2006). Conflict and control: gender symmetry and asymmetry in domestic violence. Violence Against Women, 12(11), 1003-1018. https://doi.org/10.1177/1077801206293328

Kim, J.-Y., \& Emery, C. (2003). Marital power, conflict, norm consensus, and marital violence in a nationally representative sample of Korean couples. Journal of Interpersonal Violence, 18(2), $197-219$. https://doi.org/10.1177/0886260502238735

Kiss, L. B., Schraiber, L. B., \& D’Oliveira, A. F. P. L. (2007). Possibilidades de uma rede intersetorial de atendimento a mulheres em situação de violência. Interface (Botucatu), 11(23), 485-501. https://doi.org/10.1590/S141432832007000300007

Kronbauer, J. F., \& Meneghel, S. N. (2005). Perfil da violência de gênero perpetrada por companheiro. Revista de Saúde Pública, 39(5), 695-701. https://doi.org/10.1590/S0034-89102005000500001

Lourenço, L. M., Baptista, M. N., Almeida, A. A., Basílio, C., Koga, B. M., Hashimoto, J. K. F. et al. (2013). Panorama da violência entre parceiros íntimos: uma revisão crítica da literatura. Interamerican Journal of Psychology, 47(1), 91-99. Recuperado de https://journal.sipsych.org/index.php/IJP/article/view/205

McWhirter, P. T. (2010). Differential therapeutic outcomes of community-based group interventions for women and children exposed to intimate partner violence. Journal of Interpersonal Violence, 26(12), 2457-2482. https://doi.org/10.1177/0886260510383026

Marasca, A. R., Colossi, P. M., \& Falcke, D. (2013). Violência conjugal e família de origem: uma revisão sistemática da literatura de 2006 a 2011. Temas em Psicologia, 21(1), 221-243. https://doi.org/10.9788/TP2013.1-16

Martes, A. C. B., Arretche, M., Melo, M., \& Ribeiro, P. M. (1999). Modelo de avaliação de programas sociais prioritários: relatório final. Campinas, SP: Programa de Apoio à Gestão Social no Brasil. Recuprerado de http://www. paho.org/bra/index.php?option=com_docman\&task=doc_details\&gid=557\&Itemid

Meneghel, S. N., Bairros, F., Mueller, B., Monteiro, D., Oliveira, L. P., \& Collaziol, M. E. (2011). Rotas críticas de mulheres em situação de violência: depoimentos de mulheres e operadores em Porto Alegre, Rio Grande do Sul, Brasil. Cadernos de Saúde Pública, 27(4), 743-752. https://doi.org/10.1590/S0102-311X2011000400013

Minayo, M. C. S. (2007). A inclusão da violência na agenda da saúde: trajetória histórica. Ciência e Saúde Coletiva, 119 (suppl), 1259-1267. https://doi.org/

Monteiro, M. F. G., \& Zaluar, A. (2012). Violência contra a mulher e a violação dos direitos humanos. Reprodução \& Climatério, 27(3), 91-97. https://doi.org/10.1590/S1413-81232006000500015

Mosmann, C. P., \& Wagner, A. (2008). Dimensiones de la conyugalidad y de la parentalidad: un modelo correlacional. Revista Intercontinental de Psicología y Educación, 10, 79-103. Recuperado de http://www.redalyc.org/ articulo.oa?id=80212387005 
Narvaz, M. (2010). Grupos multifamiliares: história e conceitos. Contextos Clínicos, 3(1), 1-9. Recuperado de http:// pepsic.bvsalud.org/scielo.php?script=sci_arttext\&pid=S1983-34822010000100001

Narvaz, M. (2005). Submissão e resistência: Explodindo o discurso patriarcal da dominação feminina (Dissertação de Mestrado). Universidade Federal do Rio Grande do Sul, Porto Alegre, RS.

Narvaz, M. G., \& Koller, S. H. (2006). Famílias e patriarcado: da prescrição normativa à subversão criativa. Psicologia \& Sociedade, 18(1), 49-55. https://doi.org/10.1590/S0102-71822006000100007

Nascimento, E. F. G. A., Ribeiro, A. P., \& Souza, E. R. (2014). Percepções e práticas de profissionais de saúde de Angola sobre a violência contra a mulher na relação conjugal. Cadernos de Saúde Pública, 30(6), 1229-1238. https://doi.org/10.1590/0102-311X00103613

Nunam, A. (2004). Violência doméstica entre casais homossexuais: o segundo armário? Psico, 35(1), 69-78.

Olabuénaga, J. R. (1999). Metodologia de la investigación cualitativa. Bilbao: Universidad de Deusto.

Olinto, G., \& Oliveira, Z. L. C. (2004). A inserção no trabalho segundo a condição na família: Dados da PNAD 2001 para o Brasil urbano. Mulher e Trabalho, 4, 31-44. Recuperado de http://ridi.ibict.br/handle/123456789/79

Oliveira, D. C., \& Souza, L. (2006). Gênero e violência conjugal: concepções de psicólogos. Estudos e Pesquisas em Psicologia, 6(2), 34-50. Recuperado de http://pepsic.bvsalud.org/pdf/epp/v6n2/v6n2a04.pdf

Organização Mundial da Saúde - OMS. (2002). Relatório mundial da saúde: saúde mental: nova concepção, nova esperança. Lisboa: Ministério da Saúde. Recuperado de http://www.who.int/whr/2001/en/whr01_djmessage_po.pdf

Overlien, C. (2010). Children exposed to domestic violence: conclusions from the literature and challenges ahead. Journal of Social Work, 10(1), 80-97. https://doi.org/10.1177/1468017309350663

Peinado, A., Moura, C., Almeida, I. A., Santos, M., \& Gaspar, T. (2011). Violência doméstica: uma abordagem teórica sob a perspectiva das ciências sociais [Trabalho de Curso]. Universidade de Lisboa, Portugal. Recuperado de http://www.psicologia.pt/artigos/textos/TL0206.pdf

Reichenheim, M., Dias, A., \& Moraes, C. (2006). Co-ocorrência de violência física conjugal e contra filhos em serviços de saúde. Revista de Saúde Pública, 40(4), 595-603. https:/ /doi.org/10.1590/S0034-89102006000500007

Saffioti, H. I. (2001). Contribuições feministas para o estudo da violência de gênero. Cadernos Pagu, (16), 115-136. https://doi.org/10.1590/S0104-83332001000100007

Saforcada, E. (2010). Perspectiva ecológico-sistêmica da saúde. In J. C. Sarriera, \& E. Saforcada (Orgs.), Introdução à psicologia comunitária (pp. 49-75). Porto Alegre, RS: Sulina.

Scarparo, H., \& Guareschi, N. (2007). Psicologia social comunitária e formação profissional. Psicologia \& Sociedade, 19(2), 100-108. Recuperado de http://www.scielo.br/pdf/psoc/v19nspe2/a2519ns2.pdf

Senra, C. M. G. (2009). Psicólogos sociais em uma instituição pública de assistência social: Analisando estratégias de enfrentamento (Tese de doutorado). ,Pontifícia Universidade Católica de Campinas, São Paulo. Recuperado de http://www.bibliotecadigital.puc-campinas.edu.br/tde_busca/arquivo.php?codArquivo=473

Silva, J. G., Valadares, F. C., \& Souza, E. R. (2013). O desafio de compreender a consequência fatal da violência em dois municípios brasileiros. Interface (Botucatu), 17(46), 535-547. https://doi.org/10.1590/S1414-32832013005000022

Silva, J. V., \& Corgozinho, J. P. (2011). Atuação do psicólogo, SUAS/CRAS e psicologia social comunitária: possíveis articulações. Psicologia \& Sociedade, 23(n spe), 12-21. https:// doi.org/10.1590/S0102-71822011000400003

Silva, R. B., \& Carvalhaes, F. F. (2016). Psicologia e políticas públicas: impasses e reinvenções. Psicologia \& Sociedade, 28(2), 247-256. https://doi.org/10.1590/1807-03102016v28n2p247

Soares, L. E. (2002). A eficácia pragmática da sensibilidade antropológica e a inversão do modelo defensivo: Observações sobre o lugar do simbólico na política pública de segurança. In M. Corrêa (Ed.), Gênero e cidadania (21-30). Campinas, SP: Núcleo de Estudos de Gênero Pagu.

Souza, C. (2006). Políticas públicas: uma revisão da literatura. Sociologias, 8(16), 20-45. https://doi.org/10.1590/ S1517-45222006000200003

Straus, M. A. (1979). Measuring intrafamily conflict and violence: The Conflict Tactics (CT) Scales. Journal of Marriage and the Family, 41(1), 75-88. https://doi.org/10.2307/351733

Straus, M., \& Gelles, R. (1990). Physical violence in American families. New Brunswick, NJ: Transaction. 
Teixeira, R. P (1997). Repensando a psicologia clínica. Paidéia (Ribeirão Preto), (12-13), 51-62. https://doi. org/10.1590/S0103-863X1997000100005

Turato, E.G. (2004). A questão da complementaridade das diferenças entre métodos quantitativos e qualitativos de pesquisa: Uma discussão epistemológica necessária. In S. Grubits, \& J. A. V. Noguiera (Eds.), Método qualitativo: epistemologia, complementaridades e campos de aplicação (pp. 17-52). Campinas, SP: Vetor.

Vasconcelos, E. M. (2011). Os psicológos e sua inserção no SUAS: da sensação inicial de perda de identidade ao reconhecimento de uma nova profissionalidade e de suas bases teóricas. In R. Morgado, E. M. Vasconcelos, \& J. Garcia (Eds.), Cadernos de assistência social: contribuições para a proteção básica e proteção especial (Vol. 1). Resende, RJ: Secretaria Municipal de Assistência Social e Direitos Humanos.

Villela, W. V., \& Lago, T. (2007). Conquistas e desafios no atendimento das mulheres que sofreram violência sexual. Cadernos de Saúde Pública, 23(2), 471-475. https://doi.org/10.1590/S0102-311X2007000200025

Waiselfisz, J. J. (2012). Mapa da violência 2012: homicídio de mulheres no Brasil [Caderno complementar 1]. São Paulo, SP: Instituto Sangari. Recuperado de http://www.mapadaviolencia.org.br/pdf2012/mapa2012_mulher.pdf

Walker, L. E. (1979). The battered woman. New York, NY: Harper \& Row.

\section{Kamêni Iung Rolim}

Psicóloga pelas Faculdades Integradas de Taquara (Faccat), Taquara - RS. Brasil. MBA em Comportamento Humano nas Organizações pelas Faccat e Mestre em Psicologia Clínica pela Universidade do Vale do Rio dos Sinos (Unisinos), São Leopoldo - RS. Brasil.

E-mail: kameniiungrolim@gmail.com

Denise Falcke

Psicóloga, Professora do Programa de Pós-graduação e do curso de Psicologia da Universidade do Vale do Rio dos Sinos (Unisinos), São Leopoldo - RS. Brasil.

E-mail: dfalcke@unisinos.br

Endereço para envio de correspondência:

Av. Unisinos, 950, Cristo Rei, CEP: 93022-750.

São Leopoldo - RS. Brasil.

Recebido 01/09/2016

Reformulação 02/08/2017

Aprovado 13/09/2017

Received 09/01/2016

Reformulated $08 / 02 / 2017$

Approved 09/13/2017

Recebido 01/09/2016

Reformulado 02/08/2017

Aceptado 13/09/2017 
Como citar: Rolim, K. I., \& Falcke, D. (2017). Violência conjugal, políticas públicas e rede de atendimento: percepção de psicólogos(as). Psicologia: Ciência e Profissão, 37(4), 939-955. 10.1590/1982-3703003332016

How to cite: Rolim, K. I., \& Falcke, D. (2017). Conjugal violence, public policies and service network: psychologists' perceptions. Psicologia: Ciência e Profissão, 37(4), 939-955. 10.1590/1982-3703003332016

Cómo citar: Rolim, K. I., \& Falcke, D. (2017). La violencia conyugal, las políticas públicas y la red de servicio: percepción de psicólogos. Psicologia: Ciência e Profissão, 37(4), 939-955. 10.1590/1982-3703003332016 